\title{
ANALISIS FOTO UDARA DENGAN MULTICOPTER DI DAERAH PENGHASIL PASIR BESI KARANGWUNI, TEMON, KULON PROGO
}

\author{
Indreswari Suroso \\ Program Studi Aeronautika \\ Sekolah Tinggi Teknologi Kedirgantaraan Yogyakarta \\ Jalan Parangtritis Km 4,5 Yogyakarta \\ No. Hp.: 085729024759, E-mail: indreswari.suroso@gmail.com
}

\begin{abstract}
ABSTRAK
Penelitian ini dilakukan di daerah yang memiliki potensi pasir besi, yaitu di daerah Karangwuni, Kecamatan Temon, Kabupaten Kulon Progo. Tujuan penelitian ini adalah untuk meneliti permukaan wilayah daerah penghasil pasir besi terbesar di Kulon Progo. Spesifikasi drone yang digunakan penelitian ini adalah dengan spesifikasi frame: F450; pengendali penerbangan: DJI Naza M-Lite; propeller: 1045 Prop; sepeda motor: brushless sunnsky 980 kVa; ESC: Skywalker 40 Ampere 3s; baterai: Ace 3s Gens 5000mAH; remote: Turnigy 9XR dengan Frsky Tanseiver; dan kamera: Xiaomi Yi 4k edisi Internasional. Cara drone melakukan pemetaan adalah dengan merekam gambar permukaan wilayah. Drone selesai dirakit, lalu diuji terbang. Jika drone telah terbang dengan sempurna, dilanjutkan dengan penambahan kamera di sisi bawah. Gambar permukaan area menggunakan kamera yang dipasang pada drone. Sebelum memetakan dengan drone, drone terlebih dahulu diuji lagi. Tahap awal perakitan adalah pemilihan komponen. Drone ini memiliki ketinggian dari 70 hingga $100 \mathrm{~m}$ dengan durasi hingga 10 menit menggunakan payload drone multicopter $1,5 \mathrm{~kg}$. Drone ini menggunakan kamera DJI Naza M-Lite sehingga drone dapat memotret area seluas $1,5 \mathrm{~km}$. Hasil penelitian foto udara pada pemetaan di daerah penghasil pasir besi terbesar di Kulon Progo ini adalah ternyata daerah tersebut berpasir dan sangat gersang sehingga tidak dapat dijadikan lahan pertanian. Pemerintah Kulon Progo memberikan izin untuk penambangan pasir besi dikarenakan lahan ini sudah tidak cocok untuk lahan pertanian seperti dahulu lagi.
\end{abstract}

Kata kunci: foto udara, multicopter, Kulon Progo, drone, pemetaan

\section{ABSTRACT}

Aerial Photo Analysis Using Multicopters in the Iron-Sand Producing Area in Karangwuni, Temon, Kulon Progo. This research was conducted in areas that have the potential for ironsand, which is in Karangwuni village, Temon Subdistrict, Kulon Progo regency. The aim of this research is to examine the surface of the largest iron-sand producing areas in Kulon Progo. The specifications of the drones used in this research are as follows: frame :F450; Flight Control : DJI Naza M-Lite; Propeller: 1045 Prop; Motorcycle: brushless sunnsky $980 \mathrm{kVa}$; ESC: Skywalker 40 Ampere 3s; Battery: Ace 3s Gens 5000mAH; Remote: Turnigy 9XR together with Frsky Tanseiver; and Camera: Xiaomi Yi 4k international edition. The drone made the mapping by recording the surface of the area. Once the drone was assembled, it was tested to fly. When the drone has flown perfectly, a camera was added on the lower side. So, the image of the surface were mapped using the camera which was attached to the drone. Before mapping the area using the drone, drone was tested again. The initial step of assembling was to choose the component. The drone could fly up to 70 meters until 100 meters with a duration up to 10 minutes using the payload drone multicopter weighed 1.5 kilograms. The result of this aerial photo analysis on mapping the largest iron-sand producing area in Kulon Progo regency showed that the area mapped are very sandy and very arid, therefore it cannot be used for an agricultural land. The 
government of Kulon Progo regency sets a regulation that this area could be used as an ironsand mining because this land is no longer suitable for an agricultural land as in previous times.

Keywords: aerial photo, multicopter, Kulon Progo, drone, mapping

\section{PENDAHULUAN}

Drone sebagai pesawat tanpa pilot sangat populer di kalangan peneliti untuk memotret suatu area yang akan dipelajari dari udara. Penelitian ini dilakukan di daerah yang memiliki potensi pasir besi, yaitu di daerah Karangwuni, Temon, Kulon Progo. Daerah Karangwuni memiliki potensi tinggi untuk pasir besi sehingga peneliti ingin memotret daerah ini dari udara untuk melihat potensi keberadaan pasir tersebut. Potensi material pasir besi ini ketika digali sedalam $4 \mathrm{~m}$ dan dilakukan dengan penelitian Energy Discharge Spectrometry menunjukkan bahwa komposisi besi yang ada memiliki kadar $76 \%$. Kadar pasir besi sangat tinggi diperoleh dari analisis komposisi kimia. Hal ini yang membuat peneliti berkeinginan membuat foto udara di daerah Karangwuni, Temon, Kulon Progo, Yogyakarta.

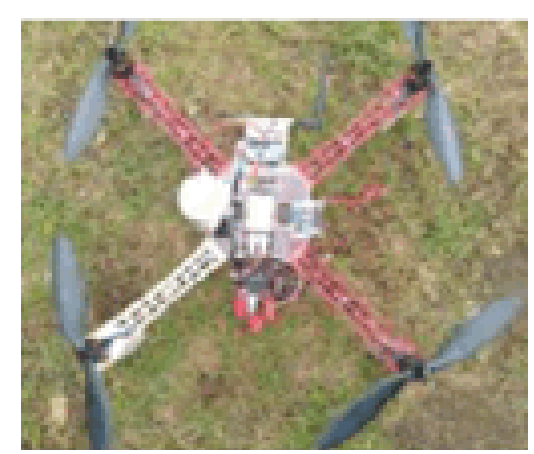

Gambar 1 Quadcopter (Suroso \& Irmawan, 2019)

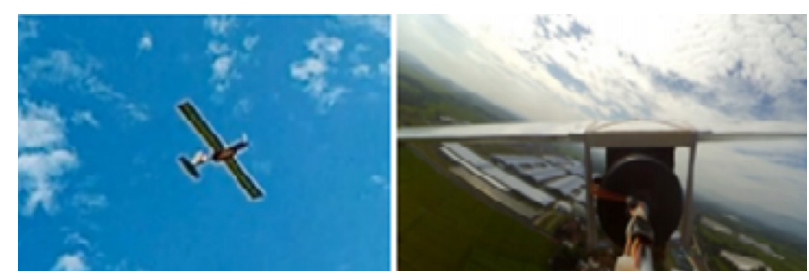

Gambar 2 Fixed Wing in Autonomous

(Thua \&Gavrilova, 2016)
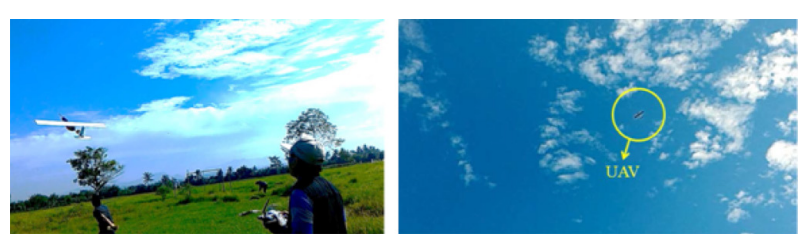

Gambar 3 UAV lepas landas dengan peluncuran tangan pada uji penerbangan dan UAV terbang dalam mode otomatis pada ketinggian 100 m. (Ariyanto et al., 2017)

Drone yang digunakan dalam penelitian ini memiliki empat baling-baling yang digunakan untuk memetakan landasan pacu. Adapun kelebihan drone jenis ini adalah hasil foto udara yang jernih dan drone dapat beroperasi sekitar 10 sampai 20 menit. Drone dalam penelitian ini seperti yang terlihat pada Gambar 1. Sayap yang tetap dalam bentuk otonom dapat dilihat seperti pada Gambar 2. Unmanned Aerial Vehicle (UAV) akan dirancang dan dibuat menggunakan bahan yang ekonomis. Perintah lintasan yang harus diikuti oleh UAV dalam bentuk persegi panjang dengan ketinggian 100 M seperti yang ditunjukkan pada Gambar 3.

Penelitian ini menggunakan multirotor yang bertujuan untuk membandingkan resolusi tinggi dan Ebee (Marcaccio, Markle, \& Chow-Fraser, 2016). UAV digunakan dengan pertimbangan biaya yang rendah dan beratnya juga rendah, yang bisa digunakan untuk pengiriman paket online (Haque, Muhammad, Swarnaker, \& Arifuzzaman, 2014). Penelitian ini mendesain drone dengan sayap seperti serangga atau capung untuk mengurangi kebisingan ketika drone beroperasi (Noda et al., 2018). Drone dirancang dengan sistem pemrograman komputer (Hovland, 2015). Sementara itu, quadcopter digunakan dengan sistem simulasi dan model matematika (N \& Sankaralingam, 
2016). UAV semacam ini ternyata bisa dimanfaatkan untuk memetakan foto udara di 985 titik dengan lahan seluas 344 hektar di Turki (Yaprak, Yildirim, \& Susam, 2017)

Penelitian ini merancang quadcopter seberat $1,5 \mathrm{~kg}$ dan dipasang di kapal dengan bantuan laptop untuk keperluan streaming (Gordon, Okoy, Onojo, \& Onuekwusi, 2016). Penelitian pemetaan foto udara dengan quadcopter dilakukan di pintu masuk Radar Congot, Temon, Kulon Progo (Suroso, 2018c). Penelitian ini menggunakan drone tipe sayap tetap dengan biaya rendah, tetapi mampu menghasilkan gambar yang baik (Ariyanto, Setiawan, Prabowo, Haryanto, \& Munadi, 2018). Desain quadcopter dengan menggunakan algoritma dan diterapkan untuk pemetaan baik di dunia militer maupun sipil (Ostojic, Stankonvi, \& Tejic, 2015). Studi terhadap UAV dilakukan untuk memetakan lingkungan tiga dimensi (Evan \& Maarten, 2018). UAV juga digunakan untuk memetakan area berbahaya di Nagano (Matsusitha, Arai, Tsukada, \& Furumoto, 2017). Addala dan Rao melakukan studi tentang drone dengan penggunaan wifi $3 \mathrm{G}$ dan $2 \mathrm{G}$ (Addala \& Rao, 2016).

Tipe hexacopter dapat digunakan untuk mendapatkan hasil gambar yang baik dengan cara menurunkan model permukaan digital dan orthopoto. (Puttock, Cunliffe, Anderson, \& Brazier, 2015). Penelitian tentang drone yang menggunakan sayap tetap dengan lokasi di Kotabaru, Lampung, untuk mendapatkan hasil gambar yang baik telah diterapkan oleh Suroso dan Irmawan (Suroso \& Irmawan, 2018). Sementara itu, keilmuan tentang aerial photography dengan penginderaan jauh menggunakan alat seperti drone telah berkembang sejak 30 tahun yang lalu (Molina, 2017). Penggunaan quadcopter untuk membuat foto udara di daerah berbahaya telah dilakukan oleh Dhanalaksmi, et. al, yaitu di daerah rawan bencana dan di sekitar daerah operasi militer (Dhanalakshmi, Shalini, \& Nivedha, 2019). Desain kontrol PID dengan $7^{0}$ kebebasan digunakan untuk mendapatkan hasil desain drone yang berkualitas baik (Heredia et al., 2014). UAV 3D dirancang untuk mendapatkan pendaratan yang relatif baik dan pendaratan yang stabil tanpa harus menggunakan GPS (Lange, Sunderhauf, \& Protzel, 2009). Multicopter yang dianggap memadai adalah yang telah menggunakan sistem geometri dan baling-baling dengan sistem algoritmik (Du, Schulz, Zhu, Bickel, \& Matusik, 2016). Penelitian ini menggunakan multicopter untuk memanfaatkan area yang tercemar (Chang, Wang, Chang, Liang, \& Lin, 2016). Anweiler dan Piwowarski merancang sebuah desain drone berukuran 750 gr dengan harga terjangkau (Anweiler \& Piwowarski, 2017). Drone yang menggunakan empat propeller pernah digunakan dalam pemetaan jalur selatan menuju bandara baru Yogyakarta melalui Desa Plumbon, Kecamatan Temon, Kabupaten Kulon Progo (Suroso, 2018b).

Pemetaan daerah rawan bencana dengan drone multicopter di daerah longsor dan banjir di wilayah Girimulyo, Kulon Progo membutuhkan tenaga yang ekstra dikarenakan banyaknya kawasan jurang di daerah tersebut (Suroso, 2018a). Penelitian ini menggunakan drone multicopter di daerah rawan bencana di Somangari, Kaligesing, Purworejo. Penelitian yang bersifat kerja sama telah dilakukan oleh Pemda Purworejo dengan STTKD Yogyakarta dalam rangka pemetaan daerah longsor (Prasetyo $\&$ Suroso, 2018). Pemetaan dengan drone yang dilakukan di daerah Kulon Progo yang rawan longsor sangat menjadi prioritas BPBD Pemda Kulon Progo yang telah bekerja sama dengan 
STTKD Yogyakarta dalam penelitian (Suroso, 2019). Dari uraian tersebut, bisa dimengerti betapa drone bisa sangat beragam jenis dan kegunaannya. Dengan demikian, perumusan masalahnya adalah bagaimana drone dapat memetakan daerah penambangan pasir besi yang dulunya merupakan lahan pertanian.

\section{PEMBAHASAN}

Langkah awal yang dilakukan adalah menggambar desain multicopter dengan ukuran seperti yang ditunjukkan pada Gambar 4 dan Gambar 5. Desain penelitian selanjutnya adalah membuat perakitan multicopter. Setelah dirakit, multicopter dicoba kapabilitasnya dengan serangkaian uji coba. Drone dalam penelitian ini seperti yang ditunjukkan Gambar 6 memiliki tipe multicopter yang digunakan untuk pemetaan di daerah yang memiliki potensi penambangan pasir besi, yaitu di daerah Karangwuni, Temon, Kulon Progo. Pemerintah Daerah Kulon Progo merasa sangat tertolong dengan penelitian ini karena objek penelitian dilakukan di daerah yang memiliki potensi pasir besi, yaitu di daerah Karangwuni, Temon, Kulon Progo. Hal ini dapat terwujud karena Pemerintah Daerah Kulon Progo telah bekerja sama dengan STTKD Yogyakarta di bidang pendidikan, penelitian, dan pengabdian kepada masyarakat. Drone yang dihasilkan dalam penelitian ini bersifat stabil. Pembeda penelitian ini dari penelitian lain yang relevan adalah bahwa desain multicopter ini dirancang untuk menahan kecepatan angin yang kuat dan multicopter ini tetap bisa terbang stabil sehingga menghasilkan gambar pemetaan yang baik. Berikut ini adalah keterangan hasil dari penelitian drone tersebut. Gambar 7 menunjukkan drone dalam persiapan penerbangan awal, kemudian disusul dengan gambar 8 yang menunjukkan drone terbang rendah. Gambar 9 menampilkan penambangan pasir besi dari arah utara dengan ketinggian 70 meter di atas tanah. Foto penambangan pasir besi dari utara dengan ketinggian 75 meter di atas tanah.

Gambar 10 adalah foto yang memperlihatkan kondisi penambangan pasir besi dari arah barat dengan ketinggian 75 meter di atas tanah. Gambar 11 adalah hasil foto penambangan pasir besi dari barat dengan drone berada pada ketinggian 70 meter di atas tanah.

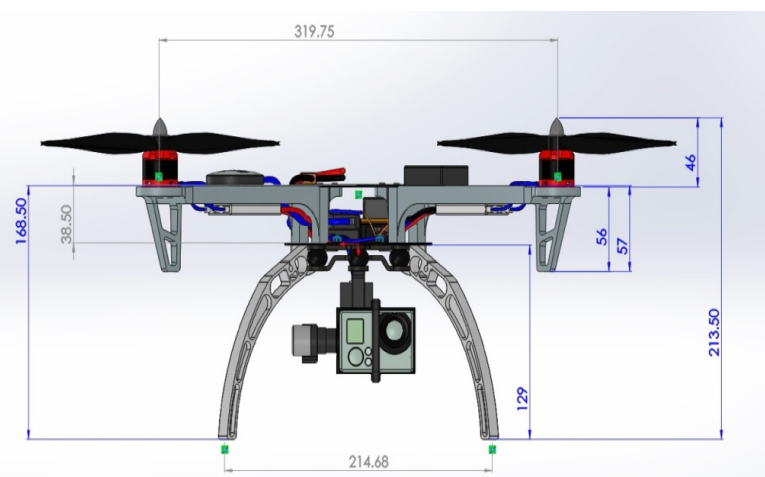

Gambar 4 Dimensi multicopter tampak depan

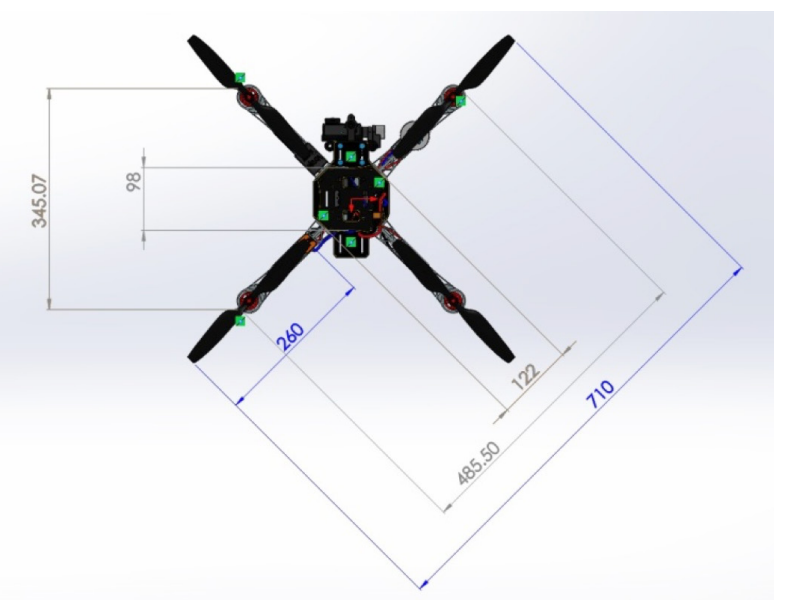

Gambar 5 Dimensi multicopter tampak atas 


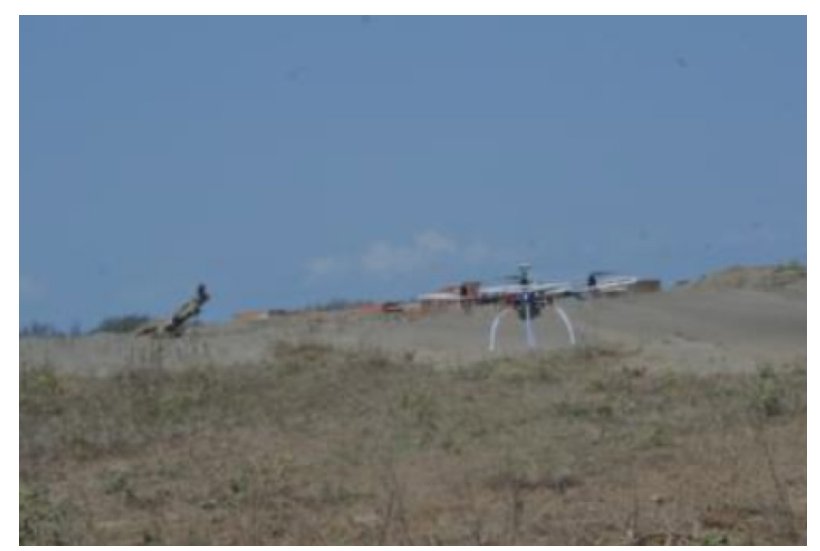

Gambar 6 Multicopter

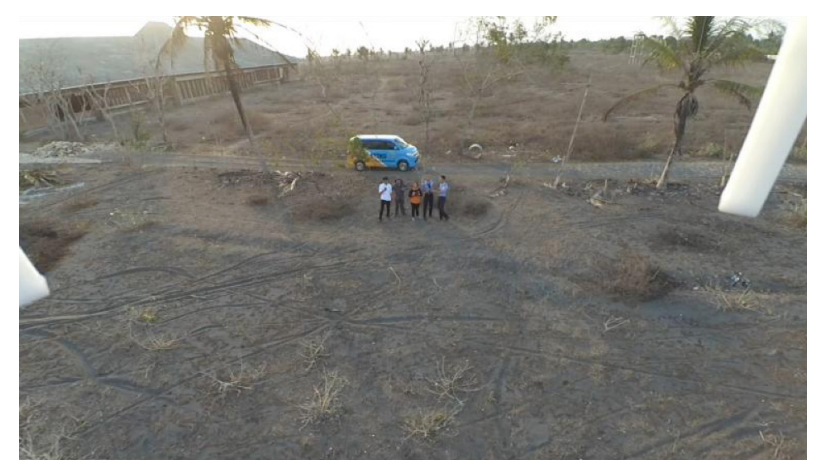

Gambar 7 Terbang awal multicopter

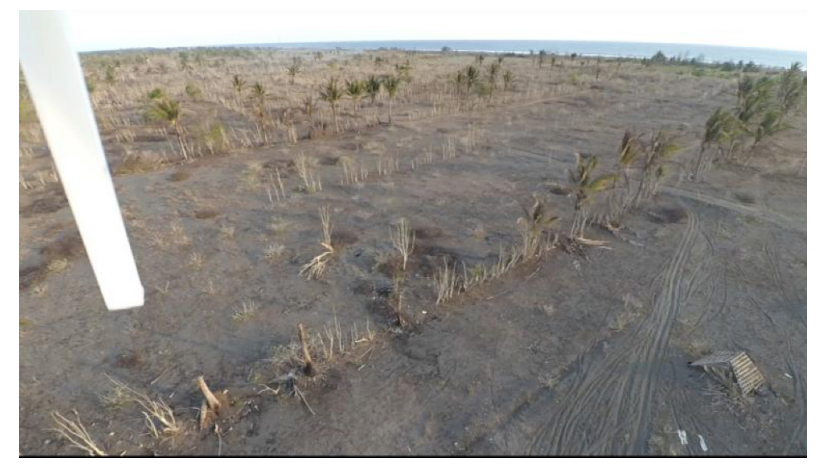

Gambar 8 Gambar foto udara dengan ketinggian 75 m dilihat dari sisi utara

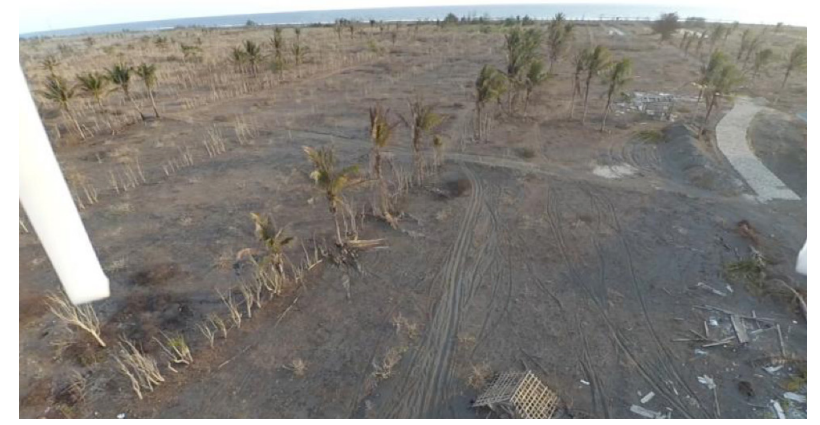

Gambar 9 Gambar foto udara dengan ketinggian 70 m dilihat dari sisi utara

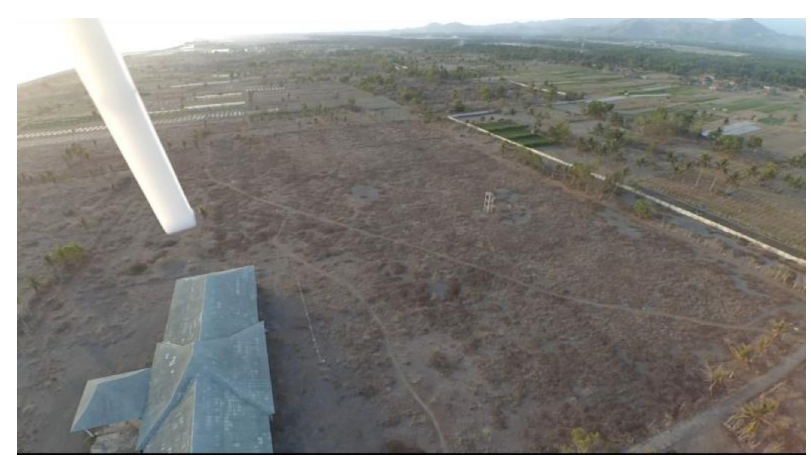

Gambar 10 Gambar foto udara dengan ketinggian 70 m dilihat dari sisi barat

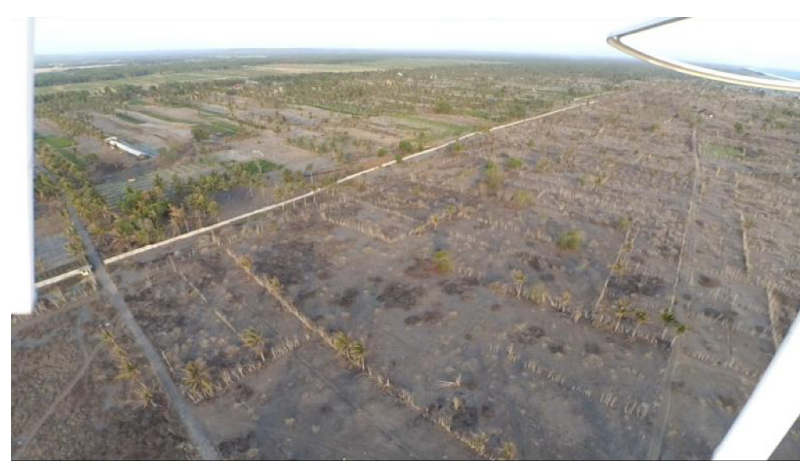

Gambar 11 Gambar foto udara dengan ketinggian 70 m dilihat dari sisi timur

\section{SIMPULAN}

Proses foto udara dengan menggunaakan drone dimulai dengan perakitan multicopter terlebih dahulu. Setelah selesai perakitan, multicopter diuji coba. Drone dalam penelitian ini memiliki tipe multicopter yang digunakan untuk memetakan foto udara suatu daerah yang memiliki potensi pasir besi, yaitu di daerah Karangwuni, Temon, Kulon Progo. Hal ini dilakukan karena penting untuk mengetahui keadaan penambangan pasir yang dulunya merupakan lahan pertanian. Drone multicopter hasil rakitan ini dapat terbang dari 70 hingga $100 \mathrm{~m}$ selama 10 menit, sedangkan multicopter drone muatan sebesar $1,5 \mathrm{~kg}$. Ketinggian multicopter ini mencapai ketinggian $100 \mathrm{~m}$ di atas permukaan tanah dan waktu penerbangan 10 menit dengan baterai 5000 $\mathrm{mAH}$. Semakin tinggi kualitas drone maka semakin lama drone tersebut dapat terbang dan hasil foto udaranya lebih baik dikarenakan drone 
memiliki spesifikasi sebagai berikut. Pengendali penerbangan: DJI Naza M-Lite; baterai: Ace 3s Gens 5000mAH; remote: Turnigy 9XR dengan Frsky Tanseiver; dan kamera: Xiaomi Yi 4k edisi Internasional. Hasil penelitian foto udara pada pemetaan di daerah penghasil pasir besi terbesar di Kulon Progo ini adalah daerah berpasir dan sangat gersang sehingga tidak dapat dijadikan lahan pertanian. Dengan adanya lahan gersang di daerah ini, Pemerintah Daerah Kulon Progo memberikan izin untuk penambangan pasir besi dikarenakan lahan ini sudah tidak cocok untuk lahan pertanian seperti dahulu lagi.

\section{UCAPAN TERIMA KASIH}

Penulis menyampaikan terima kasih kepada Bapak Marsda TNI Purn. H. Udin Kurniadi, S.E., M.M. (alm.) dan pimpinan Sekolah Tinggi Teknologi Kedirgantaraan Yogyakarta.

\section{KEPUSTAKAAN}

Addala, B. G., \& Rao, V. (2016). Flying Drone Wifi Communication. International Journal of Advance Research in Computer Science and Management Studies, 4(9), 111-116.

Anweiler, S., \& Piwowarski, D. (2017). Multicopter Platform Prototype For Environmental Monitoring. Journal of Cleaner Production, 155 , 204-211.

Ariyanto, M., Setiawan, J. D., Munadi, \& Prabowo, T. (2017). Uji Terbang Autonomous Low Cost Fixed Wing UAV Menggunakan PID Compensator. ROTASI, 19(4), 231-236.

Ariyanto, M., Setiawan, J. D., Prabowo, T., Haryanto, I., \& Munadi. (2018). Design of a Low-Cost Fixed Wing UAV. MATEC Web of Conferences 159, 02045. https://doi.org/10.1051/ matecconf/201815902045

Chang, C. C., Wang, J. L., Chang, C. Y., Liang, M. C., \& Lin, M. R. (2016). Development of a Multicopter-Carried Whole Air Sampling Apparatus and Its Applications in Environmental Studies. Chemosphere, 144, 484-492.

Dhanalakshmi, B., Shalini, E., \& Nivedha, M. (2019). Power Management System and Theft Detection Using Internet of Things (IoT). IOSR Journal of Computer Engineering (IOSR-JCE), 21(2), 48-52.
Du, T., Schulz, A., Zhu, B., Bickel, B., \& Matusik, W. (2016). Computational Multicopter Design. ACM Trans Graph, 35(6), 1-10.

Evan, T., \& Maarten, U. D. H. (2018). 3D MultiCopter Navigation and Mapping Using GPS, Inertial, and LiDAR. Journal of the Institute of Navigation, 63(2), 205-220.

Gordon, Okoy, A., Onojo, J., \& Onuekwusi, N. (2016). Design and Implementation of a Real Time Wireless Quadcopter for Rescue Operations. American Journal of Engineering Research (AJER), 5(9), 130-138.

Haque, M. R., Muhammad, M., Swarnaker, D., \& Arifuzzaman, M. (2014). Autonomous Quadcopter For Product Home Delivery. In International Conference on Electrical Engineering and Information \& Communication Technology.

Heredia, G., Jimenez-Cano, A. E., Sanchez, I., Llorente, D., Vega, V., Braga, J., \& Ollero, A. (2014). Control of a multirotor outdoor aerial manipulator. IEEE/RSJ International Conference on Intelligent Robots and Systems, 3417-3422.

Hovland, V. M. M. O. G. (2015). Multicopter Design Optimization and Validation Modeling. Identi cation and Control, 36(2), 67-79.

Lange, S., Sunderhauf, N., \& Protzel, P. (2009). A Vision Based Onboard Approach for Landing and Position Control of an Autonomous Multirotor UAV in GPS-denied Environments. International Conference on Advanced Robotics, 1-6.

Marcaccio, J. V., Markle, C. E., \& Chow-Fraser, P. (2016). Use of Fixed-Wing and Multi-Rotor Unmanned Aerial Vehicles to Map Dynamic Changes in a Freshwater Marsh. Journal Unmanned Vehicle System, 4, 193-202.

Matsusitha, E., Arai, K., Tsukada, C., \& Furumoto, Y. (2017). Use of aerial image to 3D-disaster prevention map by multicopter (Nagano City Imoi). In AIP Proceedings 1892. https://doi. org/10.10631/1.5005671

Molina, C. (2017). Unmanned Aerial Systems for Photogrammetry and Remote Sensing: A Review. ISPRS Journal of Photogrammetry and remote Sensing, 92, 79-97.

N, S. K., \& Sankaralingam, K. (2016). Design And Control Implementation of Quadcopter. International Journal of Mechanical And Production Engineering, 4(5).

Noda, Y., Nakata, T., Ikeda, T., Chen, D., Yoshinaga, Y., Ishibashi, K., ... Liu, H. (2018). Development of Bio-Inspired Low-Noise Propeller for a Drone. Journal of Robotics and Mechatronics, 30(3), 337-347. 
Ostojic, J., Stankonvi, S., \& Tejic, B. (2015). Design Control and Aplication of Quadcopter. International Journal of Industrial Engineering and Management (IJIEM), 6(1), 43-48.

Prasetyo, E. E., \& Suroso, I. (2018). Analisis Pemetaan Daerah Rawan Longsor Dengan Drone Type Multicopter di Somangari Kecamatan Kaligesing Kabupaten Purworejo. Teknika STTKD: Jurnal Teknik, Elektronik, Engine, 5(2), 5-15.

Puttock, A. K., Cunliffe, A. M., Anderson, K., \& Brazier, R. E. (2015). Aerial photography collected with a multirotor drone reveals impact of Eurasian beaver reintroduction on ecosystem structure. Journal of Unmanned Vehicle System, $3,123-130$.

Suroso, I. (2018a). Analisis Pemetaan Daerah Rawan Banjir dan Longsor dengan Drone Type Multicopter di Girimulyo, Kabupaten Kulon Progo. Teknika STTKD: Jurnal Teknik, Elektronik, Engine, 5(1), 34-43.

Suroso, I. (2018b). Analisis Peran Unmanned Aerial Vehicle Jenis Multicopter dalam Meningkatkan Dunia Fotografi Udara di Lokasi Jalur Selatan Menuju Calon Bandara Baru di Kulon Progo. REKAM: Jurnal Fotografi, Televisi, dan Animasi, 14(1), 17-25.

Suroso, I. (2018c). Analysis of Mapping Multicopter Drones In The Entrance Area Of Prospective New Airports In Congot, Temon, Kulon Progo, Yogyakarta. Journal of Applied Geospatial Information, 2(2), 130-134.

Suroso, I. (2019). Analysis of Mapping Area of Flood With Drone Type Multicopter in Girimulyo, Kulon Progo. In IOP Conference Series: Earth and Environmental Science, 271(1), 012013. IOP Publishing.

Suroso, I., \& Irmawan, E. (2018). Analysis Of Aerial Photography With Drone Type Fixed Wing in Kotabaru, Lampung. Journal of Applied Geospatial Information, 2(1), 102-107.

Suroso, I., \& Irmawan, E. (2019). Analysis of UAV Multicopter of Air Photography in New Yogyakarta International Airports. TELKOMNIKA, 17(1), 521-528.

Thua, K. M., \& Gavrilova, A. I. (2016). Designing and Modeling of Quadcopter Control System Using L1 Adaptive Control. International Symposium, 528-535. Diambil dari www.scincedirect.com

Yaprak, S., Yildirim, O., \& Susam, T. (2017). UAV Based Agricultural Planning and Landslide Monitoring. Journal of Land Use, Mobility ND Environment, 10(3). 
